\title{
Reforming the Cancer Drug Fund
}

\author{
Focus on drugs that might be shown to be cost effective
}

\author{
Martin Buxton emeritus professor ${ }^{1}$, Louise Longworth reader in health economics ${ }^{1}$, James Raftery \\ professor of health technology assessment ${ }^{2}$, Mark Sculpher professor of health economics ${ }^{3}$, Adrian \\ Towse director ${ }^{4}$
}

${ }^{1}$ Brunel University London, London, UK; ${ }^{2}$ University of Southampton, Southampton, UK; ${ }^{3}$ Centre for Health Economics, University of York, York, UK; ${ }^{4}$ Office of Health Economics, London, UK

The Cancer Drug Fund was originally conceived as a temporary measure, until value based pricing for drugs was introduced, to give NHS cancer patients access to drugs not approved by NICE. Spending on these drugs rose from less than the $£ 50 \mathrm{~m}(€ 63 \mathrm{~m}$; $\$ 79 \mathrm{~m}$ ) budgeted for the first year in 2010-11 to well over $£ 200 \mathrm{~m}$ in 2013-14, and the budget for the scheme-now extended for a further two years—will reach $£ 280 \mathrm{~m}$ by $2016 .{ }^{1}$ The recent changes to the fund recognise the impossibility, within any sensible budget limit, of providing all the new cancer drugs that offer possible benefit to patients. More radical changes are needed to the working of the fund, given the failure to introduce value based pricing, so that it deals with the underlying problem of inadequate information on the effectiveness and cost effectiveness of new cancer drugs when used in the NHS.

A recent The BMJ briefing identified major problems with the fund. ${ }^{2}$ The opportunity costs in terms of the treatments that cannot, as a result, be afforded elsewhere in the NHS are substantial, with consequent decrements to other patients' health. Its operation undermines the role of the National Institute for Health and Care Excellence (NICE). A rejection from NICE on the grounds that a drug is not cost effective (at the price proposed by the company) means little if the NHS funds it anyway through the Cancer Drug Fund. The fund's existence means that companies have no incentive to compromise on list price, offer a patient access scheme that would justify a NICE recommendation, or conduct further research.

Following its recent consultation the fund has proposed several reforms. It will introduce a rationing process that will use a more limited categorisation of the additional benefit (principally in terms of survival) and the cost (simply that of the drug) to prioritise the drugs on its list so that the fund remains within budget. ${ }^{2}$ In other words, it will do a crude reassessment of the cost effectiveness of the drug - something that NICE has already assessed and found unacceptable. This process will continue to undermine NICE, duplicate effort, and distort allocation of NHS resources while failing to support the development of cost effective drugs from which patients could benefit.
A better process is needed. We propose that the fund should focus on those cancer drugs that may be cost effective but for which current evidence is insufficient. The process could be as follows:

- NICE considers new drugs as at present

- It identifies cancer drugs for which evidence is too uncertain for a positive recommendation but further research might show they are cost effective

- These drugs are considered by a joint NICE-NHS England group that, with expert advice, decides whether at the manufacturer's price, further research is feasible and would justify its cost

- The group also decides whether in the meantime the drug should be generally available through the Cancer Drug Fund or only to patients involved in the research

- When the research is complete, NICE would reappraise the evidence and decide whether the drug should now be recommended as cost effective

- If, as is likely, the number of drugs suitable for further research still exceeded the capacity for funding, prioritisation would be on the basis of the potential value to the NHS of the additional research.

As well as cancer experts, the joint NICE-NHS England group would need to include methods specialists, who could ensure that any proposed data collection-whether from observational studies or a formal randomised trial—obtained the maximum evidential value from using the drug. This evidence generation would need to be a serious and feasible exercise not simply an excuse to start using the drug, as arguably occurred with new treatments for multiple sclerosis. ${ }^{45}$

The fund would cover the costs of the drugs, with a flexible pricing agreement. ${ }^{6}$ The additional costs of the research, which if it is to be robust may be substantial, would need to come from other sources. The presumption should be that the manufacturer should fund and, where feasible, undertake the research because 
it is designed to show that the drug is cost effective at the company's price. Other possible sources for these research funds include the pharmaceutical industry as a whole through the rebated income from companies under the current Pharmaceutical Price Regulation Scheme ${ }^{7}$; NHS funds allocated to research through the National Institute for Health Research, and other sources of research funding intended to encourage and support pharmaceutical innovation. If the public sector funds the research, it would need to be clear how the NHS shares the return on that investment, which would obviously be linked to the price it pays for the products.

This would not be an easy process, and there are many details that would need to be agreed. However, by helping to identify those promising cancer drugs for which more research could reduce the uncertainty about cost effectiveness, the Cancer Drug Fund would support a rational revised process. This could prioritise the funding of cancer drugs to serve not just today's cancer patients but all patients seeking care from the NHS in the short and longer term.

Logically such a process should not be limited to cancer drugs, but if its value could be shown for cancer there is no reason why its remit and funding could not be extended in the future. The UK life sciences minister has just launched a "wide ranging review of the way new drugs and medical devices are developed and adopted in the UK" with the intention of speeding up clinical trials and NHS patient access to new treatments. Such a review should consider an extended role for the process we suggest.

Competing interests: We have read and understood BMJ policy on declaration of interests and declare the following potentially relevant interests: MB and LL have been members of a NICE Technology Appraisal Committee which through the NICE Technology Appraisal
Programme provides guidance to the NHS including on drug reimbursement. MB has been member of NICE's steering group for value based assessment and a member of a panel providing advice to NICE's Early Scientific Advice Programme. LL has received research grants from drug companies and from NICE. MB and MS have been members of various ad hoc advisory boards for drug companies, including those sponsoring cancer drugs. JR has been a member of an ad hoc advisory group for a drug company. MS has undertaken paid consultancy for drug companies, including those sponsoring cancer drugs. AT is director of Office of Health Economics, which receives funding from the Association of the British Pharmaceutical Industry and undertakes research and consulting work for drug companies. He was also a member of NICE's value based assessment working group.

Provenance and peer review: Commissioned; not externally peer reviewed.

1 Appleby J. The Cancer Drugs Fund: inequitable and inefficient? www.kingsfund.org.uk/ blog/2014/09/cancer-drugs-fund-inequitable-and-inefficient

blog/2014/09/cancer-drugs-fund-inequitable-and-inefficient.
Jack A. Which way now for the Cancer Drugs Fund? BMJ 2014;349:g5524.

3 NHS England. Standard operating procedures: the Cancer Drugs Fund (CDF). 2014. www.england.nhs.uk/wp-content/uploads/2014/11/sop-cdf-1114.pdf.

4 Claxton K, Palmer SJ, Longworth L, Bojke L, Griffin S, McKenna C,et al. Informing a decision framework for when NICE should recommend the use of health technologies only in the context of an appropriately designed programme of evidence development. Health Technol Assess 2012;16:1-342.

5 Raftery J. Multiple sclerosis risk sharing scheme: a costly failure. BMJ 2010;340:c1672.

6 Garrison LP Jr, Towse A, Briggs A, de Pouvourville G, Grueger J, Mohr PE, et al. Performance-based risk-sharing arrangements-good practices for design, implementation, and evaluation: report of the ISPOR good practices for performance-based risk-sharing arrangements task force. Value Health 2013;16:703-19.

7 Department of Health, Association of the British Pharmaceutical Industry. The Pharmaceutical Price Regulation Scheme 2014. www.gov.uk/government/uploads/system/ uploads/attachment_data/file/282523/Pharmaceutical_Price_Regulation.pdf.

8 Ward A. UK life sciences minister races to boost medicines. Financial Times 2014 Nov 23. www.ft.com/cms/s/0/b0289044-7173-11e4-818e-00144feabdc0.html.

Cite this as: BMJ 2014;349:g7276

๑ BMJ Publishing Group Ltd 2014 